Delft University of Technology

\title{
Challenges in the Transition Towards a Sustainable City: The Case of GO2Zero
}

Bekebrede, Geertje; van Bueren, Ellen; Wenzler, Ivo; van Veen, Linda

DOI

10.1007/978-3-319-91902-7_7

Publication date

2018

Document Version

Accepted author manuscript

Published in

Simulation Gaming. Applications for Sustainable Cities and Smart Infrastructures

\section{Citation (APA)}

Bekebrede, G., van Bueren, E., Wenzler, I., \& van Veen, L. (2018). Challenges in the Transition Towards a Sustainable City: The Case of GO2Zero. In H. Lukosch, G. Bekebrede, \& R. Kortmann (Eds.), Simulation Gaming. Applications for Sustainable Cities and Smart Infrastructures: proceedings of 48th International Simulation and Gaming Association Conference, ISAGA 2017, Delft, The Netherlands, July 10-14, 2017, Revised Selected Papers (pp. 67-74). (Lecture Notes in Computer Science; Vol. 10825). Springer Science+Business Media. https://doi.org/10.1007/978-3-319-91902-7_7

\section{Important note}

To cite this publication, please use the final published version (if applicable).

Please check the document version above.

\section{Copyright}

Other than for strictly personal use, it is not permitted to download, forward or distribute the text or part of it, without the consent of the author(s) and/or copyright holder(s), unless the work is under an open content license such as Creative Commons.

\section{Takedown policy}

Please contact us and provide details if you believe this document breaches copyrights.

We will remove access to the work immediately and investigate your claim. 


\title{
Challenges in the transition towards a sustainable city: the case of GO2Zero
}

\author{
Geertje Bekebrede, ${ }^{1}$, Ellen van Bueren ${ }^{2}$, Ivo Wenzler ${ }^{2}$, Linda van Veen ${ }^{1}$ \\ ${ }^{1}$ Faculty of Technology Policy and Management, Delft University of Technology, Delft, \\ The Netherlands \\ ${ }^{2}$ Faculty of Architecture, Delft University of Technology, Delft, The Netherlands
}

\{G.bekebrede@tudelft.nl\}

\begin{abstract}
Cities face a challenging task in reducing $\mathrm{CO}_{2}$ emissions. Multiple technical solutions on district level as well as household level are available; multiple stakeholders with different values and possibilities to intervene are involved; and their actions highly influence the performance. To get a better understanding of these complexities and to contribute to a community-based transition process towards a $\mathrm{CO}_{2}$ city, a simulation game was developed. This game, GO2Zero, represents an abstract district that is challenged to reduce the $\mathrm{CO}_{2}$ emission to zero. Multiple stakeholders take actions, observe the challenges, and deal with these challenges with the final objective a sustainable district. This paper illustrates the first sessions with this game and show that different strategies of stakeholders lead to different challenges, ways to solve these, and a variety of outcomes.
\end{abstract}

Keywords: $\mathrm{CO}_{2}$ emissions, simulation game, sustainability, table top game

\section{Introduction}

The depletion of fossil fuel sources for our energy systems requires new ways and new sources to fulfil our energy demand. More importantly these sources have a large influence on the $\mathrm{CO}_{2}$ emission. Other sources than fossil fuel ones (wind, sun, biomass) and related technologies (wind turbines, solar cells, biomass combustion) are available and implemented. At this moment, this is done insufficiently. A large transition towards more sustainable energy systems is necessary. This requires not only the use of renewable sources but requires a more holistic approach that addresses cost savings, energy efficiency and institutional innovation as well.

The current transition process is scattered. Although the urgency for this transition is well known, stakeholders act alone and their actions and implementations are limited to what they individually can do. Is it possible to coordinate a collaborative transition process, how would the roles of stakeholders change, and what does this mean for the sustainability? 
To test and explore different strategies, it was decided to develop a simulation game about the transition process with the aim of reducing $\mathrm{CO}_{2}$ emissions on a district level. Simulation gaming is considered as an approach to freely experiment with different strategies and experience and reflect on the consequences of one's actions [1](Duke and Geurts 2004). Furthermore, a simulation game can be considered as a complex system in itself, that makes it possible to represent a real world complex system [2,3] (Bekebrede 2010, Frank 2014). In the game, multiple stakeholders on a district level can work together, experience, and learn how a transition process can be organized, who needs to take the lead and how to achieve collaboration and alignment among stakeholders. This game is intended for European city stakeholders. Before this game could go life it had been tested with students from Tilburg University.

This paper presents the results of these student sessions. The main questions are: does this game provide enough freedom to experiment with different strategies, does it result in a variety of outcomes, is it a game nice to play?

We will first introduce the challenges in the transition towards a sustainable city. In chapter 3, we will describe the game GO2Zero, which is developed by Delft University of Technology in cooperation with DNV GL. Chapter 4 describes the research approach, and the results of the sessions are described in Chapter 5. We end with the conclusions that the game provides the possibility to experience challenges in the transition processes towards sustainable cities and could be a starting point for a collaborative design of this process.

\section{Transition towards sustainable energy cities}

Cities can be considered as complex socio-technical systems [4] (Holland 1995). Due to the characteristics of these complex systems, planning and steering the system towards a new system state is difficult and maybe even impossible. Looking at energy transition processes on a district level, we observe a network of a variety of stakeholders, formally and informally dependent on each other, and many technical and managerial possibilities, which are highly connected and interacting. That means the system can show emergent behavior, which could be unexpected and undesirable.

Main actors on a district level are the municipality, inhabitants of the district, the social housing corporation, businesses, but also the energy network operator and energy companies. These stakeholders operate on different levels and make decisions based on different values. Whereas a citizen mainly focusses on its direct living environment, a network operator or energy company reaches a larger geographical level. Although, in general, the actors would agree that sustainability is important, the ways in which this can be achieved varies from high-level top-down interventions to small-scale bottom-up initiatives.

In addition, the variety of technical solutions and the relationships between them are large. A number of possibilities are available, from reducing energy consumption by insulation, double glazing, and energy saving appliances, to producing energy on a household scale (e.g heat pumps, photovoltaic (PV) panels) and a district scale (e.g. PV farms, wind farms, and using rest heat from industry), or changing energy sources 
from using gas towards using heat. The problem with these measures is that they could negatively influence each other. If households insulate their houses and install heat pumps, the demand for heat from the network will decline and investing in a heat network will not be efficient. Placing multiple PV panels on roofs might require changing the capacity of the electricity network.

Finally, the technical system and the stakeholder network interact. Owners decide about placing PV panels, which require an action from network operators to adapt the networks; subsidies from a municipality steer the selection of measures causing different performances of the system. These interactions lead to emergent behavior on the level of the district and consequently on the national and international scale.

\section{Challenges}

Getting a city towards a state of zero $\mathrm{CO}_{2}$ emission faces some challenges.

- Stakeholders must invest first, while the return of investment is uncertain. PV panels will not be optimally used when they were closed from the network with insufficient capacity.

- The transition is a kind of chicken and egg story; on the one hand, the electricity network must be ready and on the other hand stakeholders need to invest in sustainable measures. It is not clear where to start.

- If everybody is deciding on their own, coordination problems will occur. Who needs to take this initiative to coordinate this process?

- Many stakeholders look at municipalities to organize this process. A municipality can follow a more top-down approach in which the local government in leading (by rules and regulations, incentives etc.) or follow a more bottom-up approach where the individual stakeholders take the lead and take actions based on their priorities and expectations.

\section{The game GO2Zero}

GO2Zero is a multiplayer tabletop game, developed as part of the EU project Cityzen. The development followed the game design philosophy of Harteveld [5] (2011) and the design approach of Duke and Geurts [1] (2004). The main objective of the game is to get a better understanding of the challenges of the transition process towards zero emissions in cities and to provide an experiential space to explore different transition strategies. In the development, we started with a thorough system analysis, including interviews with different stakeholders in Europe to understand the main variables, relations and challenges. In the design of the game, we set some clear boundaries to make the game more playable and more focused. Therefore, the transportation sector was left outside the scope, just as the commercial businesses in a district.

The game GO2Zero simulates a transition process towards sustainable energy. Multiple players, divided over different roles need to take actions to reduce energy consumption, increase sustainable production and make the district $\mathrm{CO} 2$ free. A 
board, with 12 houses with their families and gas and electricity networks, represents the district (See Figure 2). All households have four piles of fiches representing the energy consumption (heat and electricity), the energy production, and the CO2 emissions. The potential local production areas also have a place on the map.

The participants play the families, municipality, grid operator, technology contractors, housing corporation and the local energy company. Half of the families rent a house from the housing corporation and the other half are house owners. All households have a grey energy contract with a national energy company (played by the facilitator) to start with. The grid operator is responsible for ensuring sufficient capacity on the grid. The needed capacity will change due to actions of the families and the housing corporation, but also by newly installed production capacity of the local energy company. The participants are placed at different tables in the room, with a placemat containing information about their personal situation, available contracts, and assets. They are allowed to move around and communicate with each other.

The challenge in the game is to reduce the $\mathrm{CO}_{2}$ emissions in the district back to ZERO! Additionally, participants should achieve energy consumption reduction by $50 \%$, and produce all energy locally. The transition process is not determined yet, so the participants need to think about strategies to reduce energy demand, and produce green energy locally. Cooperation and coordination is necessary, but they must consider their personal values as well as their financial possibilities and consumption pattern.

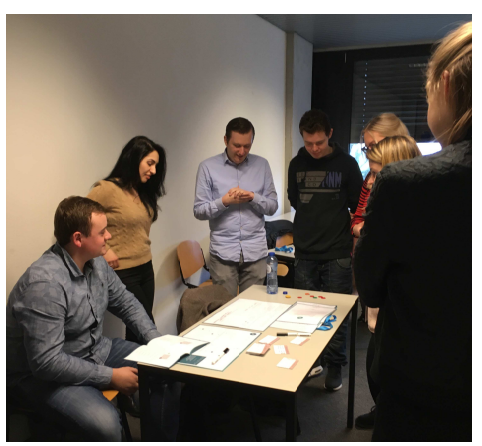

Figure 1 Discussion with grid operators (picture used with permission)

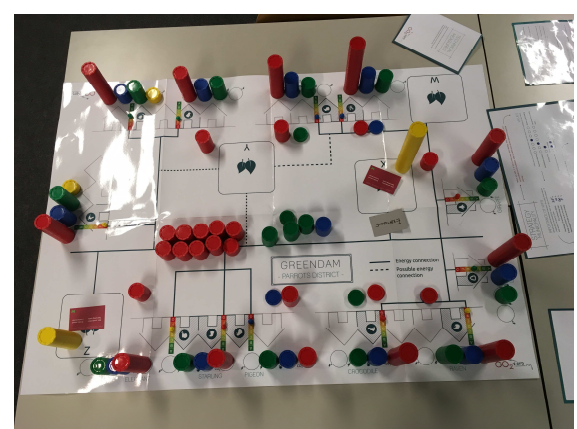

Figure 2 Representation of the district. The piles represent $\mathrm{CO}_{2}$ emission, energy use and consumption per household

A gaming session of GO2zero starts with a briefing about the background of the energy problem and an introduction to the game. The game starts with a strategy phase where participants have time to read the information and develop a strategy. The game takes place in several rounds consisting of three steps: 1) payments, 2) negotiation, and 3) consumption. In the first step, households receive their salary and they have to pay their rent, energy bills, grid costs and municipality taxes. During the second step, all stakeholders can buy technology assets, negotiate about costs, make appointments, change contracts, and organize community meetings (See Figure 1). In the third step, the city map is adapted to the new situation. A complete gaming session has four rounds. After the rounds, the final score is registered and all participants have to count their money and get an overview of their individual situation. 
Then a debriefing starts, during which participants share and discuss their results, followed by sharing of emotions surfaced during the game, and reflect on the overall outcomes of the game. Further, they discuss what has happened, which challenges they faced and how this could be done differently. Finally, together they look forward to what this could mean for the transition process in the real cities.

\section{Participants and research set-up}

The game was play-tested with the municipality of Amsterdam (The Netherlands) and Dubrovnik (Croatia). From these sessions, the design of the game and materials have been improved, like the game flow and amount of possible measures. In this paper, we focus on the realism and utility of the final design with student sessions.

\subsection{Participants}

The game was played with first year students following a public policy making course at Tilburg University. At the end of the course, they played GO2Zero, to experience the policy making and decision-making concepts discussed in the lectures in a simulated real-life situation. In total 46 Dutch students played the game. The average age was 19,6 years (sd. 2.4), more women than men played the game, respectively $64 \%$ and $36 \%$. They were randomly divided in three groups consisting of 15,15 and 16 students. This was an optimal number of players for the game.

\subsection{Research set up}

As this is one of the first sessions of the final game, we were especially interested in the game play, the possibilities within the game, and experiences of players. To collect data about these points, we used the following methods:

- Game results; each round results of the situation in the game were collected.

- Game observations: each group had one general game leader and one or two teachers to observe the game play and listen to the discussion between participants.

- Postgame questionnaire which focused on the game experiences and changing perspectives about the transition process. All participants received a link to an online survey.

\section{Results}

The results are divided in game outcomes to observe the varieties of strategies and game experiences to present the game play according to participants. 


\subsection{Game outcomes}

All groups started from the same position, which means that the houses have a low energy label $(\mathrm{G}$ or $\mathrm{H})$, which is an indicator of the sustainability of the house, and they use non-sustainable energy sources for their consumption. We observed different strategies and results between the three teams. Table 1 shows the outcomes on the three main indicators. In general, none of the groups reached the final objective on any of performance indicators. This was hardly possible, as the game has been designed for four rounds of playing and due to time limitations, we played two rounds.

Table 1 Results of the different groups on the three main key performance indicators.

\begin{tabular}{|c|c|c|c|c|}
\hline & Target & Team 1 & Team 2 & Team 3 \\
\hline $\mathrm{CO} 2$ reduction & $100 \%$ & $46.7 \%$ & $45.5 \%$ & $33.4 \%$ \\
\hline $\begin{array}{l}\text { Reduction energy } \\
\text { consumption }\end{array}$ & $50 \%$ & $27.0 \%$ & $33.6 \%$ & $14.8 \%$ \\
\hline$\%$ local produced & $100 \%$ & $29.5 \%$ & $6.7 \%$ & $3.0 \%(52 \%)^{1}$ \\
\hline
\end{tabular}

${ }^{1}$ Group 3 build a couple of local production assets, which had not been connected to the network at the end of the session. Otherwise, the local production would have been $52 \%$.

Team one clearly focused on reducing $\mathrm{CO}_{2}$ emissions by changing the grey energy contracts to a contract with energy generated by nuclear power. This had a large impact on $\mathrm{CO}_{2}$ emissions. Secondly, the households focused on energy reduction and local production via PV panels. They did this without any communication with the grid operator. Consequently, the network had insufficient capacity to deal with the new production. In the second round, the grid operator invested in increasing the grid capacity and the households applied energy reduction measures. This lead to an overly dimensioned network and a waste of resources.

The second group focused most on the reduction of energy. Together with some sustainable energy contracts, they were about halfway the $\mathrm{CO}_{2}$ reduction targets and reached the highest reduction in energy use. With this group, the grid operator was also not part of the discussion about how to execute the transition. They had the idea that they could only react on the actions of others and need to follow the dynamics.

The third group had a strong grid operator, who took the leading position. To survive as a company, they had the strategy to focus on district production instead of household production. They actively discussed with the local energy company about investments in the grid and new production assets. In this session, the households had less influence and needed to pay higher grid costs. In the results, this is not yet visible, as the installed power was not connected to the grid at the end of the game. If it had been connected, the energy from local production would have been $52 \%$, which would have been substantially higher than in other groups, especially taking into account that their energy consumption was higher.

During the debriefing, it became clear that it was not so easy to align the strategies among the stakeholders. Although they share the same ambition, when it comes to 
discussing investments problems occur, which lead to a deadlock. The discussion about implementing a heat network was a good example; everybody had agreed that this was a good solution, but nobody wanted to invest. Finally, the heat network was not implemented. A second general observation was that stakeholders focused on the well-known measures as PV panels, insulation and double-glazing. They did not research other opportunities.

\subsection{Game experience}

In the postgame survey, we asked for players' experiences while playing this game. The number of responses of the postgame questionnaire was $24(51 \%)$. Table 2 presents averages of answers to the statements (on a 5-point Likert scale). The participants agree that the game was relevant $(\mathrm{M}=3.9, \mathrm{SD}=0.5)$ and they put themselves into their role $(\mathrm{M}=3.9, \mathrm{SD}=0.6)$. Further, they slightly agree on the clarity of aim, the level of detail, and the realism of dynamics. In the debriefing, we observed that the students were surprised that in reality stakeholders often do not communicate well and believed that you could take decisions only with complete information. Further, they slightly agree that they enjoyed playing the game and they would like to play again. From the reactions in the open questions, we conclude that a better introduction of the different roles is needed as students lack knowledge about different roles. In addition, they asked for more time, so they would have the opportunity to finish the game. Both points influenced their experiences.

\section{Table 2 Statistics about game play experiences}

\begin{tabular}{|l|l|l|}
\hline Statement & $\begin{array}{l}\text { Average } \\
(\mathbf{n = 2 4 )}\end{array}$ & St. deviation \\
\hline The aim of GO2Zero was clear & 3.5 & 1.0 \\
\hline The aim of GO2Zero was relevant & 3.9 & 0.5 \\
\hline I really put myself into my role & 3.9 & 0.6 \\
\hline $\begin{array}{l}\text { Given the aim of the simulation, the performance } \\
\text { indicators were sufficiently detailed }\end{array}$ & 3.5 & 1.2 \\
\hline $\begin{array}{l}\text { Given the aim of the simulation, the dynamics were } \\
\text { sufficiently realistic }\end{array}$ & 3.5 & 1.3 \\
\hline I enjoyed taking part in GO2Zero & 3.6 & 1.1 \\
\hline I would like to play GO2Zero again & 3.5 & 1.1 \\
\hline
\end{tabular}

\section{Discussion and conclusions}

The goal of the GO2Zero game is to provide more insights in the challenges of a transition process towards sustainable cities. Our observations, coupled with the results of the sessions, show that the game provides room for testing a variety of strategies and related outcomes. Further observations showed that a good alignment between different stakeholders is necessary to stimulate the transition process and to optimally use limited resources. Especially the role or involvement of a grid operator 
seemed to be critical in this transition. A second observation was that well known and easy to apply measures had been taken, like new appliances and PV panels. Other less known measures as heat pumps were not implemented.

The post survey shows that participants liked to play the game and would like to play the game again. The experience could become better if the roles had been explained better and if there was enough time to finish the game. The participants agreed that this game gave more insights in challenges of the transition process.

Based on the results, we conclude that GO2Zero represents a complex system in a playable way and gives room for discussion. More respondents are needed to measure the changing opinion about the transition process by playing this game.

\section{Acknowledgement}

The game development and sessions played have been part of the EU FP7 supported project 'City-zen, new urban energy'. The game has been developed in collaboration with DNVGL.

\section{References}

[1] Duke, R. D. and J. L. A. Geurts: Policy Games for Strategic Management: Pathways into the Unknown. Dutch University Press, Amsterdam (2004).

[2] Bekebrede, G.: Experience Complexity: A gaming approach for understanding infrastructure systems. Gildeprint Drukkerijen, Enschede (2010).

[3] Frank, A.: Establishing games, gaming and policy exercises as tools for urban and regional planning - Are we there yet? In. Duke, R.D. and Kriz, W.C., Back to the Future of Gaming, pp. 80-92. W. Bertelsmann Verlag, Bielefeld. (2014).

[4] Holland, J. H.: Hidden Order; How Adaptation Builds Complexity. AddisonWesley, Reading. (1995).

[5] Harteveld, C.: Triadic game design: Balancing Reality, Meaning and Play. Springer Verlag, London. (2011). 